\title{
MODELING FIELD GEOMETRY OF MICRO-IRRIGATION SYSTEMS
}

\author{
Sharaf, G. $\mathrm{A}^{\mathbf{1}}$, Azza A. $\mathrm{H}^{\mathbf{2}}$ and Hashiem M. M. ${ }^{3}$
}

\section{ABSTRACT}

The purpose of planning an irrigation network is to achieve suitable water distribution and to satisfy the hydraulics and economic rules. A model was developed to design, plan and manage an irrigation system subject to a number of constraints according to field geometry, soil properties, plant characteristics and irrigation system parameters. As a result, management criteria may be achieved by selecting a layout pattern and the appropriate number of shifts. The Microsoft Excel Solver tool was used to solve the partitioning part. The model divides the field into subunits. The decision variables are: 1) pipe lengths and diameters (lateral, riser, manifold, auxiliary, submain and main). 2) The total number of subunits, number of sets (subunit parallel to the main line). 3) Number of submain lines perpendicular to the main line. 4) Possible numbers of shifts and shift time. 5) List of system equipment. 6) Pump total dynamic head, system capacity and pump power. 7) Cost analysis of the system and total capital cost. The model was successfully solved the problem of partitioning the field and specifies the dimension of different parts of the micro irrigation system network. The planning of the irrigation field layout accomplished among five patterns (A through E). The validity of the model was extended to select the economic pipe sizes and estimate the system total costs in case of one shift operation policy or at a higher number of shifts to reduce the cost. Throughout a case study to plan design and management of $20 \mathrm{fed}$. $(300 \mathrm{~m}$ length and $280 \mathrm{~m}$ width) to irrigate trees $5 m x 5 m$ spacing, results indicated that pattern $E$ was the most economic option either in operating the system in one shift (the cost is 7348 LE.fed) or to reduce further cost to be 3861 L.E./fed.) in case of operate the system in four shifts. Investigating the effect of system area ranged between 5 to 50 feddan on system total cost indicated that the cost increased linearly proportional to

1. Prof. of Ag. Eng. Dept. of Soil \& Ag Chemi. Fac. of Ag. Saba - Basha Alex. Univ.

2. Senior Res. Ag. Eng. Res. Inst. Cairo Egypt.

3. Res., Ag. Eng. Res. Inst. Cairo Egypt. 
the increasing of the system area. The effect of number of shifts on total cost was also studied. The results showed that the relationship is power function where the total cost is inversely proportional to increasing the number of shifts.

\section{INTRODUCTION}

$\mathrm{P}$ lanning an irrigation network is to put a suitable layout of the piping system depending on the field shape and topography. This process has no predefine steps and depends mainly of the designer experience and sense while some economic and hydraulic considerations must be achieved. In this research the uniformity and hydraulic balance is an essential target and were considered. In the research the design criteria for flow variation within the subunit depends on distribute $20 \%$ of nominal operating pressure as recommended by Keller and Karmeli (1975), to design lateral diameter by $55 \%$ of the allowable pressure and manifold diameter by the rest of the allowable pressure, then round up the calculated diameters to the next commercial diameters.

The largest diameters confirm that the allowable pressure differences within the subunit not exceed the $20 \%$ allowable pressure and insure flow variation less than $10 \%$. The diameter of riser auxiliary, submain and main lines were estimated based on limiting velocity rule; water velocity was less than $1.5 \mathrm{~m} / \mathrm{s}$.

A few studies have been reported on the optimization of pressurized irrigation systems considering field geometry ; Abdel Wahed, (2002) proposed a method to plan drip irrigation network, his method depends on dividing the field area into similar sections which must be irrigated by the total discharge of the pump. Each section subdivided into number of subunits. The subunits could be double or single lateral.

El- Awady and Osama (1996), investigated the effective factors geometrical proportion of the plot and the economical considerations for planning of trickle irrigation networks.. In their study, they considered the subplot is square with area ranging from 5 to 10 fed., lateral length equal half of the subplot length and the submain length is equal to the 
subplot length. The results are the optimum planning, number of subplot, number of laterals, submain and main.

Ismail et al., (2001) developed MicroCAD computer package for design and planning micro irrigation systems. The planning approach depends on categorizing the planning layouts into eighteen general cases. By default, MicroCAD set maximum manifold length to $100 \mathrm{~m}$ and the maximum lateral length to $50 \mathrm{~m}$. The MicroCAD offers the option to automatically or manually modify the previous values. Beside the ability of selecting the planning category by number, any layout differ from the suggested could be applied and any modification to the suggested layout could be applied too.

Oron and Walker (1981) presented design model for sprinkler irrigation systems. Their model was based on the work of Oron and Karmeli (1979). The aims of the work were to compute the number of subunits in both directions of the field, the optimum size of subunits, and the associated diameter of the system components. The system capital and operating costs, was examined as a function of field geometry, consumptive use and pressure head at the water source. They showed that the optimum division of the field into subunits is greatly affected by the field geometry. It depends not only on the area of the field, but also on its width/length ratio and most economical size of the subunit is the square type.

Oron (1982) suggested that fields to be irrigated with permanent pressurized systems should be divided into subunits. The subunit array permits one to irrigate part of the field at a time, achieve a more uniform emitter discharge, increase flexibility in irrigation practices, select smaller pipe sizes throughout the system, and allow one to use an increasing number of emitters per plant during the growing stages.

Hassanli and Dandy (1995), proposed design model for design and operation of drip irrigation system on flat terrain. The model minimizes the sum of the capital cost of the system and the present value of operating cost. In the model, the field was divided to subunits with an assumed layout and configuration of piping system 
A few studies have been reported on planning the pressurized irrigation systems considering the field geometry and subunit size.

The main objective of the work was to develop model for design, plan and manage an irrigation system subject to a number of constraints according to field geometry, soil properties, plant characteristics and irrigation system parameters.

\section{Model Development}

\section{System components:}

This model plans a flat rectangular micro irrigation system, design the network for minimum total cost. The different layout patterns considered in the research are shown in Fig. (1). They consist of a pump and control head at the edge of the field for patterns A,B,C and at the center for patterns D,E. The piping system consists of one main line parallel to one edge of the field in the first category patterns, and two mainlines at both sides of the pump in the other pattern. The mainline deliver water from the pump to the submain pipes. The submain lines are perpendicular to mainline. Auxiliary pipes receive water from submain to manifold and then to the laterals throughout risers. Summary of these variables describing the field geometry and various constants are illustrated as follows:

\section{Integer variables:}

ne $\quad=$ number of emitters on lateral on both sides of lateral.

$\mathrm{nl}=$ number of laterals along the manifold ion both sides of the manifold

$\mathrm{NsX}=$ number of submains applying subunits parallel to the main line

$\mathrm{NsY}=$ number of subunits parallel to the submain.

Ns = number of subunits on the system

\section{Constants:}

$\begin{array}{ll}\text { SX } & \text { = field length in X direction }(\mathrm{m}) \\ \mathrm{SY} & =\text { field length in } \mathrm{Y} \text { direction }(\mathrm{m}) \\ \mathrm{se} & =\text { spacing between emitters }(\mathrm{m}) \\ \mathrm{sl} & =\text { spacing between laterals }(\mathrm{m})\end{array}$




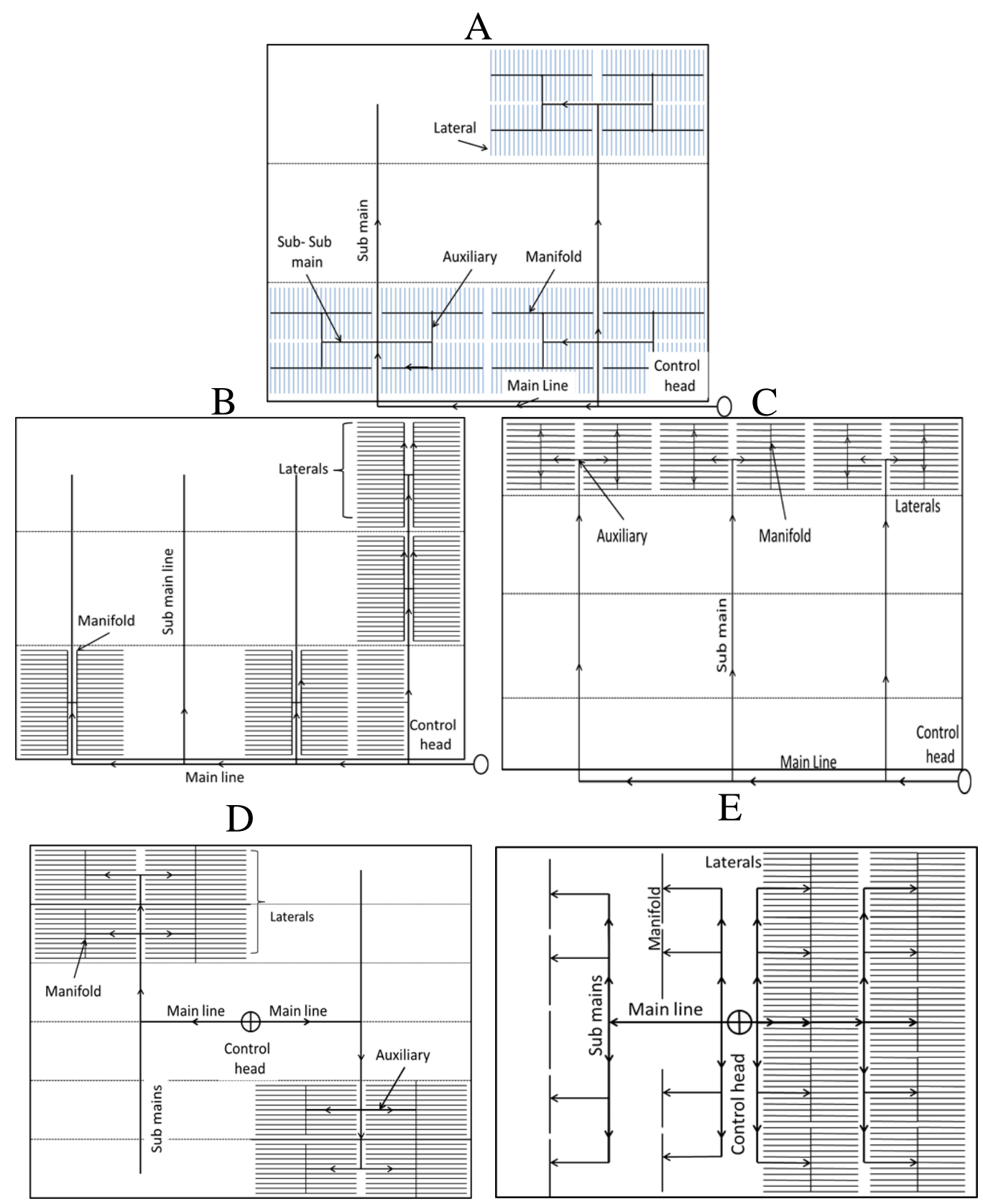

Fig (1): Layout pattern from " $A$ " to " $E$ " that the model investigated.

Planning the micro irrigation system:

The partitioning of the field geometry has been carried out using the principles of operation research as: 
Equalize:

$$
\frac{(n e . s e) \cdot(n l . s l) \cdot(2 N s X) \cdot N s Y)}{S x \cdot S y}=1
$$

Subject to:

1- Limiting lateral length

$$
50 \leq \operatorname{int}\{\text { se }(n e-1)\} \leq 100
$$

2- Limiting manifold length

$$
50 \leq \operatorname{int}\{s l(n l-1)\} \leq 100
$$

3- Defined the number of subunits in y direction: $N s Y=\frac{S Y}{n l \leqslant s l}$

4- Defined the number of subunit in $\mathrm{x}$ direction: $2 . N s X=\frac{L X}{n e s s e}$ or $N s X=\frac{L X}{n e * s e}$ depends on layout pattern ( 2 in case of two subunits on both sides of the sub main line)

5- Defined the number of subunits on the system: $\frac{2 N s X{ }_{N S} Y}{N s}=1$ or $\frac{N s X \cdot N s Y}{N s}=1$ depends on layout pattern

Based on the above criteria of planning micro irrigation system, the total number and / or total length of the field components of the distribution network can be expressed with the previous variable and constants given in Table (1).

Irrigation interval, irrigation time and number of shifts:

Irrigation interval is the time in days between the commencement of one irrigation cycle and the next. The irrigation time or duration is the length of irrigation event (The period of time during which water is being released from one set of emitters). The irrigation shifts $\left(\mathrm{N}_{\mathrm{sh}}\right)$ refers to the number of different sets of submains which are irrigated simultaneously; one shift means irrigating the entire field simultaneously. Two shifts operation involves irrigating half of the field at the same time of one shift. The model allows the number of shifts to be chosen as decision variable. Initial estimate of number of shifts is essential for specific crop, soil and irrigation system.

1- Irrigation intervals determined by identifying the depth of water which can be stored in the soil and the consumptive use of the crop as:

$$
R A W=10(f c-w p) \cdot R \cdot d r \cdot P_{W}
$$


Where:

$R A W=$ depth of water available to the crop in soil (mm)

$F c \quad=$ soil field capacity moisture content $(\%)$

$W p \quad=$ soil wilting point moisture content $(\%)$

$R \quad=$ root depth $(\mathrm{m})$

$\mathrm{Dr} \quad=$ fraction of available moisture depletion allowed (decimal)

$P_{W} \quad=$ wetted area as a percentage of total area of irrigation (\%)

The maximum irrigation interval (Iv) is estimated so that the average daily transpiration $\left(\mathrm{ET}_{\mathrm{C}}\right)$ during the beak use period in each irrigation cycle is less than or equal to the depth of water which can be stored in the root zone

$$
I v \leq \frac{R A W}{E T_{C}}
$$

2- Gross irrigation requirements $\left(G_{I R}\right)$.

$$
G_{I R}=\frac{E T_{C}}{E_{a}} \times \frac{1}{(1-L R)}
$$

Where:

Ea = irrigation system application efficiency (decimal).

LR = leaching requirements (decimal).

3- Irrigation duration (Id).

$$
I d=\frac{G_{I R} \cdot I v \cdot s e \cdot s l}{q \cdot n_{p}}
$$

Where:

$\mathrm{q}=$ emitter flow rate $(\mathrm{l} / \mathrm{h})$

$\mathrm{n}_{\mathrm{p}} \quad=$ number of emitter per plant.

4- Number of shifts per irrigation cycle $\left(\mathrm{N}_{\mathrm{sf}}\right)$.

$$
N_{s f} \leq \frac{I v \cdot D l}{I d}
$$

Where:

Dl = day length, taken as $(20 \mathrm{~h} /$ day $)$ 
Piping system diameters and lengths:

The irrigation system network consists of two types of pipes, conveyance and distribution. Lateral were considered distribution pipes, therefore; $20 \%$ of emitter operating pressure distributed as $55 \%$ on lateral and $45 \%$ on manifold. Auxiliary, riser, sub-submain, submain and mainline were considered conveyance pipes, Therefore; a limiting maximum velocity of water inside the pipe as $1.5 \mathrm{~m} / \mathrm{sec}$ was considered as the design criteria to find conveyance pipe diameters. After the pipe diameter is calculated it rounded up the next commercial pipe diameter and cost estimation based on its price.

\section{System Hydraulic Losses}

Darcy-Weisbach formula and Blassius equation were applied to determine the friction head loss within the piping system as follows:

$$
H f(i)=79844.75 \cdot L(i) \cdot Q(i)^{1.75} D(i)^{-4.75} F(i)
$$

Where:

$i \quad=$ subscript the pipe

$H f$ = friction loss along the pipe, $(\mathrm{m})$

$F \quad=$ reduction factor of the pipe as a function of outlets.

$L \quad=$ pipe length $(\mathrm{m})$

$Q \quad=$ pipe discharge $\left(\mathrm{m}^{3} / \mathrm{h}\right)$

$D=$ pipe diameter $(\mathrm{mm})$

$F \quad=$ reduction factor

The reduction factor $F$ depends on the discharge exponent of friction loss formula ( $\mathrm{m}$ ) and the number of outlet "no" in the line under consideration as:

$$
F 1=\frac{1}{m-2}+\frac{1}{n o}+\frac{\sqrt{m-4}}{6 . n o^{2}}
$$

In this study, the first outlet (emitter or lateral) was half the others spacing; therefore, the F1 has to be readjusted to another factor $F$ as:

$$
F=\frac{2 n o}{2 n o-1} * F 1-\frac{1}{2 n o-1}
$$


Table(1): Number or length of all the field components in the distribution network of all layout patterns considered in the study

\begin{tabular}{|c|c|c|c|c|c|}
\hline Items & Patten A & Pattern B & Pattern C & Pattern D & Pattern E \\
\hline Total No of emitters on the system & $\frac{S x S y}{s e . s l}$ & The same & The same & The same & The same \\
\hline Total lateral lengths on the system & $S x S y\left\{\frac{n e-1}{\text { sl } \cdot n e}\right\}$ & The same & The same & The same & The same \\
\hline End plugs for laterals & $2\left\{\frac{\text { Sx.Sy }}{\text { se.ne.sl }}\right\}$ & The same & The same & The same & The same \\
\hline Total Tees connecting lateral to riser & $\frac{\text { Sx.Sy }}{\text { se.ne.sl }}$ & The same & The same & The same & The same \\
\hline Total length of risers on the system & $S x . S y\left\{\frac{h r}{s e, n e, s l}\right\}$ & The same & The same & The same & The same \\
\hline Total Tees connecting riser to manifold & $\frac{\text { Sx.Sy }}{\text { se.ne.sl }}$ & The same & The same & The same & The same \\
\hline Total length of Maifolds pipes & $S x . S y\left\{\frac{n l-1}{n e_{*}, e_{*} n l}\right\}$ & The same & The same & The same & The same \\
\hline Tees connecting auxiliary to manifold & $\frac{S x . S y}{(s e . n e)(n l . s l)}$ & - & The same & The same & The same \\
\hline Auxiliary pipe lengths & $S x . S y\left\{\frac{0.5}{n l . s l}\right\}$ & - & The same & The same & The same \\
\hline Tees connecting auxiliary to sub-submain & - & - & - & $2 \mathrm{Ns} \mathrm{X} . \mathrm{NsY}$ & - \\
\hline Tees connecting Sub-submain to submain & - & - & - & $N s X . N s Y$ & - \\
\hline sub -Submain total length & - & - & - & $\frac{S x . S y}{n e . s e}$ & - \\
\hline Submain total length & $N s X\left\{S y-\frac{n l . s l}{2}\right\}$ & The same & $\{S y \cdot(n l . s l)\} N s X$ & $N s X\left\{s y-\frac{n l . s l}{2}\right\}$ & $(N s y-1) N s x(s l . n l)$ \\
\hline Tees connecting auxiliary to submain & $2 N s X . N s Y$ & - & - & - & $N s X . N s Y$ \\
\hline Main line total length & Sx-(ne.se) & The same & $5 x-2($ ne.se) & $S x-(n l . s l)$ & $S x-($ ne.sl $)$ \\
\hline Tees connecting submain to main & NsX & The same & The same & The same & The same \\
\hline Total No of subunits on the system & $2 N s \mathrm{~N} . \mathrm{NsY}$ & The same & The same & The same & $N s X . N s Y$ \\
\hline Total No of subunit valves & $2 N s X . N s Y$ & The same & The same & The same & $N s X . N s Y$ \\
\hline Total No of subunit pressure regulators & $2 N s X . N s Y$ & The same & The same & The same & $N s X . N s Y$ \\
\hline
\end{tabular}


Table (2): Definitions of system piping (i), system length $(L)$, discharge $(Q)$, and number of outlets $(n o)$.

\begin{tabular}{|c|c|c|c|}
\hline Pipe(i) & $\mathrm{L},(\mathrm{m})$ & $\mathrm{Q},\left(\mathrm{m}^{3} / \mathrm{h}\right)$ & Outlet No. no \\
\hline $\begin{array}{l}\text { Lateral (A,C,E,D) } \\
\text { Lateral (B) }\end{array}$ & $\begin{array}{c}0.5(n e-1) . s e \\
(n e-1) . s e\end{array}$ & $\begin{array}{c}0.5\left(\text { ne } . k H^{x}\right) \\
\left(\text { ne } . k H^{x}\right)\end{array}$ & $\begin{array}{c}\text { int. }(0.5 n e) \\
\quad(n e)\end{array}$ \\
\hline Manifold & $0.5(n l-1) . s l$ & $0.5(n l . n e) \cdot k H^{x}$ & int. $(0.5 \mathrm{nl})$ \\
\hline Riser & 0.6 & $n e \cdot k H^{x}$ & - \\
\hline Auxiliary (A,C.D,E) & 0.5 (ne.se) & (nl.ne). $k H^{x}$ & - \\
\hline Sub-sub main (A) & sl.nl/2 & 2. $(n l \cdot n e) \cdot k H^{x}$ & - \\
\hline $\begin{array}{l}\text { Submain }(A, B, C) \\
\text { Submain }(D) \\
\text { Submain }(E)\end{array}$ & $\begin{array}{c}S y-0.5(n l . s l) \\
0.5 S y-0.5(n l . s l) \\
0.5 S y-0.5(n l . s l)\end{array}$ & $\begin{array}{c}\text { 2.NsY.(nl.ne). } k H^{x} \\
N s Y .(n l \cdot n e) \cdot k H^{x} \\
0.5 . N s Y \cdot(n l \cdot n e) \cdot k H^{x}\end{array}$ & $\begin{array}{c}2 . N s Y \\
N s Y \\
\operatorname{int}(0.5 . N s Y))\end{array}$ \\
\hline $\begin{array}{l}\text { Main }(A, B, C) \\
\text { Main }(D) \\
\text { Main }(E)\end{array}$ & $\begin{array}{c}S x-(\text { ne.se }) \\
0.5 . S x-(\text { ne.se }) \\
0.5 .5 x-(\text { ne.se })\end{array}$ & 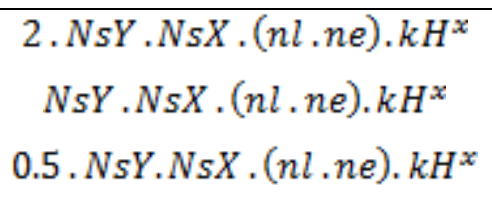 & $\begin{array}{c}\text { NsX } \\
\text { int. }(0.5 . N s X) \\
\text { int. }(0.5 . N s X)\end{array}$ \\
\hline
\end{tabular}

Minor loss due to emitter connection barb on lateral was estimated by additional length method according to SCS, (1984) by:

$$
f_{e}=1+\frac{18.91}{\text { se. } D l^{1.87}}
$$

Then lateral length $(\mathrm{L})$ changed by $\left(\mathrm{L} \cdot \frac{s e+f e}{s e}\right)$ where $D$ is lateral diameter, $(\mathrm{mm})$. and $s e$ is the distance between emitters.

Tee head loss due to connecting the network pipes was estimated according to Keller and Bliesner, (1990) by the following equation:

$$
H f_{T}=K_{T} \frac{V^{2}}{2 g} \quad \text { or } \quad 6375.5 K_{T}, Q_{T}^{2} \cdot D_{T}{ }^{-4}
$$

Where:

$V \quad=$ water velocity $(\mathrm{m} / \mathrm{s})$

$g \quad=$ acceleration of gravity $\left(\mathrm{m}^{2} / \mathrm{s}\right)$

$K_{T}=$ tee loss coefficient (1.2 from line to branch flow and 0.8 from 
branch to line flow)

$D_{T}=$ diameter of the tee, $(\mathrm{mm})$

$Q_{T}=$ discharge across the tee $\left(\mathrm{m}^{3} / \mathrm{h}\right)$.

In large areas where the field is divided into subunit, it may be essential to install pressure regulator next to auxiliary to insure uniformity of water application. The friction loss across the pressure regulator is a function of the water discharged to the subunit. The head loss across the pressure regulator estimated according to Goehring (1976) as;

$$
H F_{P R}=0.13 Q_{S U}^{2}+0.67 Q_{S U}+1.56
$$

Where:

$\mathrm{Q}_{\mathrm{SU}}=$ flow rate submitted to subunit $\left(\mathrm{m}^{3} / \mathrm{h}\right)$

Head loss across the control head was estimated according to Holzapfel et al., (1990) by;

$$
H F_{C H}=0.02 Q_{C H}^{1.474}
$$

Where:

$\mathrm{Q}_{\mathrm{CH}}=$ flow rate submitted to the system $\left(\mathrm{m}^{3} / \mathrm{h}\right)$.

Cost of the irrigation system

The cost of the irrigation system include the capital cost of piping system, pump, emitters, valves, accessories and the operating cost;

$$
Z=C_{p i}+C_{p u}+C_{e m}+C_{a c}+C_{o p}
$$

Where:

$\mathrm{Z} \quad=$ system total cost

$\mathrm{C}_{\mathrm{pi}} \quad=$ cost of piping system

$\mathrm{C}_{\mathrm{pu}} \quad=$ cost of pump

$\mathrm{C}_{\mathrm{em}} \quad=$ cost of emitters

$\mathrm{C}_{\mathrm{ac}}=$ cost of accessories and fittings

$\mathrm{C}_{\mathrm{op}} \quad=$ operating cost

The cost of pipes can be expressed as:

$$
C_{p i}=C_{l}+C_{m}+C_{r}+C_{a}+C_{s u b}+C_{m a}
$$

Where:

$\mathrm{C}_{\mathrm{pi}} \quad=$ total cost of the piping system 
$\mathrm{C}_{1} \quad=$ cost of laterals

$\mathrm{C}_{\mathrm{m}} \quad=$ cost of manifolds

$\mathrm{C}_{\mathrm{r}} \quad=$ cost of riser

$\mathrm{C}_{\mathrm{a}} \quad=$ cost of auxiliary

$\mathrm{C}_{\text {sub }}=$ cost of submain lines

$\mathrm{C}_{\mathrm{ma}}=$ cost of the main line

The system assumed to be semi automated, thus; the labor cost is small compared to the capital and energy cost.

The model subunit pipes, laterals were assumed to be laid on ground while the rest of the piping system, manifold, riser, auxiliary, submain and main are assumed to be buried. Therefore; installation cost is added to the pipe cost as $10 \%$ for laterals and $20 \%$ for the buried pipes.

The cost of pumping system $\left(\mathrm{C}_{\mathrm{pu}}\right)$ is a function of its power and discharge (Holzapfel et al., 1990) as follows:

$$
C_{p u}=K_{P}\left\{\frac{Q_{p u} \cdot H_{p u}}{270 \cdot \eta_{p}}\right\}
$$

$\mathrm{Q}_{\mathrm{pu}}=$ discharge of the pump $\left(\mathrm{m}^{3} / \mathrm{sec}\right)$, system total number of emitters/

number of shift $\mathrm{x}$ emitter flow rate

$\mathrm{H}_{\mathrm{pu}} \quad=$ Total dynamic head at the pump (m)

$\mathrm{K}_{\mathrm{P}} \quad=$ constant found by fitting a set data include the cost of various pumps

and their design head and discharge

The cost of accessories include filter unit, chemical injection tank and cost of valve for each subunit, one for each submain line and one for each main line.

The power of electric motor expressed as:

$$
P_{m}=\frac{\gamma Q_{p u} H_{p u}}{\eta_{m} \eta_{p}}
$$

Where:

$\mathrm{P}_{\mathrm{m}} \quad=$ electric motor power $(\mathrm{Kw})$

$\gamma \quad=$ specific weight of water $\left(\mathrm{N} / \mathrm{m}^{3}\right)$

$\eta_{m} \eta_{p} \quad=$ efficiency of motor and pump respectively.

The annual energy requirements $(\mathrm{kWh})$ based on annual irrigation requirements and annual operating hours of pump : 


$$
A_{e n}=2.78 \times 10^{-7} P_{m} \frac{A_{i r} S x S Y}{E_{a} Q_{p u}}
$$

Where:

$\begin{array}{ll}\mathrm{A}_{\mathrm{en}} & =\text { annual energy requirements }(\mathrm{kWh}) \\ \mathrm{A}_{\mathrm{ir}} & =\text { net annual irrigation requirements }(\mathrm{mm}) \\ \mathrm{E}_{\mathrm{a}} & =\text { irrigation system application efficiency }\end{array}$

Basic inputs to the model:

The model was run using the Microsoft Excel Solver tool. The input variables are:

1- field dimension Sx, Sy.

2- potential evapotranspiration ETo and crop coefficient, Kc or the crop consumptive use ETc.

3- percent of the wetted area Pw by the emission devices

4- emitter characteristics and flow function q, k, x, Ho.

5- application of the irrigation efficiency Ea.

6- annual irrigation requirements for the crop, $\mathrm{A}_{\mathrm{ir}}$

7- field capacity Fc and permanent wilting point wp of the soil.

8- effective depth of the root, Rz.

9- allowable depletion ratio, $\mathrm{dr}$.

10- spacing between emitters, se and lateral spacing, sl.

11- hours per day for irrigation, $\mathrm{Tr}$.

12- efficiency of the electric motor $\eta_{\mathrm{m}}$ and the pump efficiency $\eta_{\mathrm{m}}$.

13- available diameters for PVC and PE pipes, accessories and their price lists.

14- energy cost (C-kWh)

15- cost functions of the system component.

16- length of irrigation season, LSI (days)

Model assumptions:

The general configuration of pipes within the field (main and sub main lines) and within the subunit (lateral, manifold, auxiliary and riser) were layed out as given in Fig.(1) by patterns from A to E. The model was developed for a field with unknown area and unknown dimensions for which the water source is located at the edge of the area or at the center. The model can be easily applied to any size and field dimensions. 


\section{RESULTS AND DISCUSSION}

The main objective of the study is to develop model to plan, design and manage micro irrigation system characterized by economic cost with acceptable flow variation. The model was based on multiple subunit system. The influence of system area, number of shifts and layout pattern on total cost will be investigated and discussed among case study to find an optimum solution among various operating conditions.

Case study and analysis of the model results:

To validate the model; a micro-irrigation system of $20 \mathrm{fed}$. level rectangular field cultivated by trees $300 \mathrm{~m}$ x $280 \mathrm{~m}$ need to be planed, designed and managed for minimum total cost taken in to account acceptable number of shifts and flow variation using data given in Table(3).

Table. (3): Constants and input data for the case study

\begin{tabular}{|c|c|c|c|}
\hline Variable & value & Variable & value \\
\hline $\mathrm{Se}$ & $5 \mathrm{~m}$ & $\mathrm{X}$ & 0.5 \\
\hline $\mathrm{Sl}$ & $5 \mathrm{~m}$ & $\mathrm{C}_{\mathrm{em}}$ & $14.42 \mathrm{~L} . \mathrm{m} / \mathrm{unit}$ \\
\hline $\mathrm{LSI}$ & $180 \mathrm{day}$ & $\mathrm{Ho}$ & $20 \mathrm{~m}$ \\
\hline $\mathrm{Tr}$ & $20 \mathrm{hr}$ & $\mathrm{Kp}$ & 1050 \\
\hline $\mathrm{FC}$ & $20 \%$ & $\mathrm{PE}$ & $60 \%$ \\
\hline $\mathrm{Pw}$ & $10 \%$ & $\mathrm{C}-\mathrm{kWh}$ & 0.4 \\
\hline $\mathrm{Wr}$ & $50 \%$ & $\mathrm{C}-\mathrm{EP}^{1}$ & $0.5 \mathrm{~L} . \mathrm{E} . / \mathrm{UNIT}$ \\
\hline $\mathrm{R}$ & $1 \mathrm{~m}$ & $\mathrm{C}-\mathrm{PR}{ }^{2}$ & $180 \mathrm{~L} . \mathrm{E} . / \mathrm{UNIT}$ \\
\hline $\mathrm{dr}$ & $50 \%$ & $\mathrm{ET}_{\text {crop }}$ & $8 \mathrm{~mm} /$ day \\
\hline $\mathrm{K}$ & 0.008 & & \\
\hline
\end{tabular}

1 C-EP: Cost of end plug.

2 C-DR Cost of pressure regulator.

Five main runs were achieved for each of the layout patterns, A thtough E. For each run the model specifies the number of the sub main lines (Nsx) attached to the main line and number of subunit normal to the main 
line attached to the sub main line (NsY). Also, the number of emitters on laterals, the number of the laterals on the manifolds and the system total number of subunits were determined. The results of layout parameters from A to E patterns presented in Table (4). Secondary runs were archived after each main run based on the available number of shifts. For instance, according to the given input data of soil, plant, and irrigation system characteristics, the irrigation interval was 4 days and the irrigation time/shift was 5 hours. Therefore., the system could be operated just one time each 4 days as one shift or on two shifts in 10 hours or for four shifts in 20 hours continually to irrigate the whole area in one day. Another option could be in two sifts day by day or shift per day and so on. The selection of management policy depends on the available water source, labors and the cost of investment. The results of the secondary runs of each layout pattern according to the available number of shifts were given in Table (4,5 and 6) either for the management and design parameters or the cost analyses for each item of the network. Pipes, emitters, accessories and energy relative costs to the system total cost increased by increasing the number of shifts. The relative cost of the control head and pumping have a different behavior, where the relative cost decreased by increasing the number of shifts. Summarized results are given in Table (8), showed the total cost for different number of shifts at each layout pattern and the expected flow variation. Pattern E was the most economic option either in operating the system in one shift (the cost is 7348 LE. fed) or to reduce further cost to be 3861 L.E./fed.) in case of operate the system in four shifts.

To show the effect of area and number of shifts on total cost. Pattern "E" was considered for the available number of shifts. Areas ranged between 5 to 50 feddan were selected. The output results were presented in Table (7). Analyzing the results indicated that the cost increased linearly proportional to the increasing of the system area as shown in Fig. (2 a). The effect of number of shifts on total cost showed that the relationship is power function where the total cost is inversely proportional to increasing the number of shifts as given in Fig. (2 b). 
Table(4): Different layout patterns of model.

\begin{tabular}{|c|c|c|c|c|c|c|c|}
\hline \multicolumn{8}{|c|}{ Layout parameters } \\
\hline \multirow{2}{*}{\multicolumn{2}{|c|}{ Input }} & \multicolumn{6}{|c|}{ Output } \\
\hline & & & Pattern A & Pattern B & Pattern C & Pattern D & Pattern E \\
\hline Field total area & 20 fed. & No. of sub main lines NsX & 2 & 2 & 2 & 2 & 4 \\
\hline Field length in $\mathrm{X}$ direction $\mathrm{Sx}$ & $300 \mathrm{~m}$ & No. of subunit parallel to main line NsY & 4 & 4 & 4 & 2 & 4 \\
\hline Field length in $\mathrm{Y}$ direction $\mathrm{SY}$ & $280 \mathrm{M}$ & Total No. of subunit on system NS & 16 & 16 & 16 & 16 & 16 \\
\hline Distance between emitters se & $5 \mathrm{~m}$ & No. of emitters on lateral (ne) & 15 & 15 & 15 & 15 & 15 \\
\hline Distance between laterals ne & $5 \mathrm{~m}$ & No. of laterals on manifold (sl) & 14 & 14 & 14 & 14 & 14 \\
\hline
\end{tabular}

Table(5): Results of model output for management and design parameters.

\begin{tabular}{|c|c|c|c|c|c|c|c|c|c|c|c|c|c|c|}
\hline \multirow{4}{*}{ Items } & \multicolumn{14}{|c|}{ Management and design parameters } \\
\hline & \multicolumn{14}{|c|}{ Pattern } \\
\hline & \multicolumn{3}{|c|}{ A } & \multicolumn{3}{|c|}{$\mathrm{B}$} & \multicolumn{3}{|c|}{$\mathrm{C}$} & \multicolumn{2}{|l|}{$\mathrm{D}$} & \multicolumn{3}{|c|}{ E } \\
\hline & 1 shifts & 2 shifts & 4 shifts & 1 shifts & 2 shifts & 4 shifts & 1 shifts & 2 shifts & 4 shifts & 1 shifts & 2 shifts & 1 shifts & 2 shifts & 4 shifts \\
\hline Lateral diameter $(\mathrm{mm})$ & 13.6 & 13.6 & 13.6 & 15.6 & 15.6 & 15.6 & 13.6 & 13.6 & 13.6 & 13.60 & 13.6 & 13.6 & 13.6 & 13.6 \\
\hline Manifold diameter(mm) & 28.4 & 28.4 & 28.4 & 28.4 & 28.4 & 28.4 & 28.4 & 28.4 & 28.4 & 28.40 & 28.40 & 36.4 & 36.4 & 36.4 \\
\hline Riser diameter(mm) & 17.0 & 17.0 & 17.0 & 17.0 & 17.0 & 17.0 & 17.0 & 17.0 & 17.0 & 17.0 & 17.0 & 17.0 & 17.0 & 17.0 \\
\hline Auxiliary diameter(mm) & 46.4 & 46.4 & 46.4 & - & - & - & 46.4 & 46.4 & 46.4 & 46.40 & 46.6 & 59.2 & 59.2 & 59.2 \\
\hline Sub submain line diameter & - & - & - & - & - & - & - & - & - & 70.6 & 70.60 & - & - & - \\
\hline Sub maim diameter(mm) & 131.8 & 84.6 & 70.6 & 131.8 & 84.6 & 70.6 & 84.6 & 84.6 & 59.2 & 131.8 & 84.6 & 103.6 & 70.6 & 59.2 \\
\hline Main line diameter(mm) & 188.2 & 131.8 & 84.6 & 188.2 & 131.8 & 84.6 & 84.6 & 84.6 & 84.6 & 188.2 & 131.8 & 131.8 & 103.6 & 103.6 \\
\hline Total system capacity $\mathrm{m}^{3} / \mathrm{h}$ & 120.1 & 60.1 & 30.05 & 120.2 & 60.11 & 30.53 & 120.21 & 60.11 & 30.05 & 120.2 & 60.11 & 120.21 & 60.11 & 30.06 \\
\hline Total dynamic head $\mathrm{m}$ & 55.4 & 41.8 & 39.63 & 55.09 & 41.90 & 36.70 & 33.36 & 33.17 & 23.00 & 56.62 & 44.45 & 41.47 & 34.58 & 34.12 \\
\hline Pump power $\mathrm{kW}$ & 30.7 & 11.9 & 5.49 & 30.50 & 11.60 & 5.22 & 18.48 & 9.18 & 4.43 & 31.34 & 12.30 & 22.95 & 10.14 & 4.73 \\
\hline Flow variation on subunit $\%$ & \multicolumn{3}{|l|}{7.67} & \multicolumn{3}{|l|}{7.15} & \multicolumn{3}{|l|}{9.40} & \multicolumn{2}{|l|}{9.2} & \multicolumn{3}{|l|}{6.48} \\
\hline
\end{tabular}


Table(6): Results of model output for cost analyses parameters.

\begin{tabular}{|c|c|c|c|c|c|c|c|c|c|c|c|c|c|c|}
\hline \multirow{3}{*}{ Items } & \multicolumn{14}{|c|}{ Cost analyses parameters } \\
\hline & \multicolumn{3}{|c|}{$\mathrm{A}$} & \multicolumn{3}{|c|}{$\mathrm{B}$} & \multicolumn{3}{|c|}{$\mathrm{C}$} & \multicolumn{2}{|c|}{$\mathrm{D}$} & \multicolumn{3}{|c|}{$\mathrm{E}$} \\
\hline & 1 shifts & 2 shifts & 4 shifts & 1 shifts & 2 shifts & 4 shifts & 1 shifts & 2 shifts & 4 shifts & 1 shifts & 2 shifts & 1 shifts & 2 shifts & 4 shifts \\
\hline Total cost LE.fed & 9604 & 6765 & 2556 & 9938 & 7068 & 5871 & 8587 & 6536 & 5472 & 9641 & 6670 & 7348 & 4977 & 3861 \\
\hline Piping cost (\%) & 19.11 & 26.1 & 31.28 & 22.63 & 30.71 & 36.59 & 21.94 & 27.95 & 33.17 & 19.56 & 26.78 & 19.85 & 28.81 & 36.77 \\
\hline Emitters cost $(\%)$ & 24.90 & 35.5 & 43.28 & 24.07 & 33.85 & 40.75 & 27.86 & 36.6 & 43.42 & 24.81 & 35.33 & 16.01 & 23.63 & 30.46 \\
\hline Accessories cost $(\%)$ & 2.10 & 2.95 & 3.57 & 1.38 & 1.90 & 2.27 & 1.58 & 2.06 & 2.45 & 1.46 & 2.05 & 1.53 & 2.21 & 2.83 \\
\hline Head cost $(\%)$ & 21.1 & 15.4 & 9.31 & 20.93 & 14.68 & 8.8 & 24.22 & 15.87 & 9.44 & 21.57 & 15.33 & 28.3 & 20.85 & 13.38 \\
\hline Pumping cost $(\%)$ & 30.6 & 18.2 & 10.48 & 29.44 & 17.06 & 9.57 & 24.23 & 15.85 & 9.26 & 30.96 & 18.55 & 32.59 & 22.17 & 13.67 \\
\hline Energy cost $(\%)$ & 1.61 & 1.93 & 2.22 & 1.56 & 1.81 & 2.03 & 1.28 & 1.68 & 1.96 & 1.64 & 1.96 & 1.73 & 2.35 & 2.90 \\
\hline
\end{tabular}

Table (7): Output results of pattern "E” for different areas.

\begin{tabular}{|c|c|c|c|c|c|c|c|c|c|c|c|c|c|c|c|c|}
\hline \multirow[b]{2}{*}{$\begin{array}{l}\text { Area } \\
\text { (fed.) }\end{array}$} & \multirow[b]{2}{*}{$\mathrm{X}$} & \multirow[b]{2}{*}{ Y } & \multirow[b]{2}{*}{ NsX } & \multirow[b]{2}{*}{ NsY } & \multicolumn{7}{|c|}{ Cost per unit area (LE./.fed.) } & \multirow{2}{*}{$\begin{array}{c}\text { Flow } \\
\text { variation } \\
\%\end{array}$} & \multirow{2}{*}{$\begin{array}{c}\text { No. } \\
\text { of } \\
\text { units }\end{array}$} & \multirow{2}{*}{$\begin{array}{c}\text { Unit } \\
\text { area } \\
\mathrm{m}^{2} \\
\end{array}$} & \multirow{2}{*}{$\begin{array}{c}\text { Lateral } \\
\text { length } \\
\mathrm{m}\end{array}$} & \multirow[b]{2}{*}{$\begin{array}{l}\text { Manifold } \\
\text { length } \mathrm{m}\end{array}$} \\
\hline & & & & & $\begin{array}{c}1 \\
\text { shift }\end{array}$ & $\begin{array}{c}2 \\
\text { shifts }\end{array}$ & $\begin{array}{c}3 \\
\text { shifts }\end{array}$ & $\begin{array}{c}4 \\
\text { shifts }\end{array}$ & $\begin{array}{c}5 \\
\text { shifts }\end{array}$ & $\begin{array}{c}6 \\
\text { shifts }\end{array}$ & $\begin{array}{c}7 \\
\text { shifts }\end{array}$ & & & & & \\
\hline 5 & 150 & 140 & 2 & 2 & 6918 & 4836 & & & & & & 7.67 & 4 & 5250 & 35.0 & 32.5 \\
\hline 10 & 225 & 200 & 3 & 2 & 7121 & 4916 & 4116 & & & & & 5.7 & 6 & 7500 & 35.0 & 47.5 \\
\hline 15 & 315 & 200 & 3 & 2 & 7342 & 4966 & 4249 & & & & & 6.49 & 6 & 10500 & 50.0 & 47.5 \\
\hline 20 & 340 & 255 & 4 & 3 & 7391 & 5017 & 4249 & 3922 & & & & 5.78 & 12 & 7225 & 40.0 & 40.0 \\
\hline 25 & 350 & 300 & 5 & 4 & 7565 & 5099 & & 3974 & 3797 & & & 7.47 & 20 & 5250 & 32.5 & 35.0 \\
\hline 30 & 390 & 325 & 6 & 5 & 7724 & 5192 & 4438 & & 3826 & 3729 & & 4.83 & 30 & 4225 & 30.0 & 30.0 \\
\hline 35 & 420 & 350 & 7 & 5 & 7915 & & & & 3858 & & 3664 & 4.63 & 35 & 4200 & 27.5 & 32.5 \\
\hline 40 & 420 & 400 & 4 & 5 & 8091 & 5173 & & 3956 & 3671 & & & 8.73 & 20 & 8400 & 50.0 & 37.5 \\
\hline 45 & 450 & 420 & 5 & 6 & 8240 & 5206 & 4372 & & 3773 & 3576 & & 8.52 & 30 & 6400 & 42.5 & 43.5 \\
\hline 50 & 500 & 420 & 5 & 6 & 8449 & 5219 & 4355 & & 3769 & 3551 & & 6.48 & 30 & 7000 & 47.5 & 32.5 \\
\hline
\end{tabular}


Table. (8):Total cost (L.E./fed.) and flow variation of different pattern of layout and number of shift.

\begin{tabular}{|c|c|c|c|c|}
\hline Pattern & One shift & Two shifts & Four shifts & $\begin{array}{c}\text { Flow variation } \\
\%\end{array}$ \\
\hline A & 9604 & 6765 & 5546 & 7.67 \\
\hline B & 9938 & 7068 & 5871 & 7.15 \\
\hline C & 8587 & 6536 & 5472 & 9.40 \\
\hline D & 9441 & - & 6670 & 9.20 \\
\hline E & 7348 & 4977 & 3861 & 6.48 \\
\hline
\end{tabular}

Effect of area on unit area cost

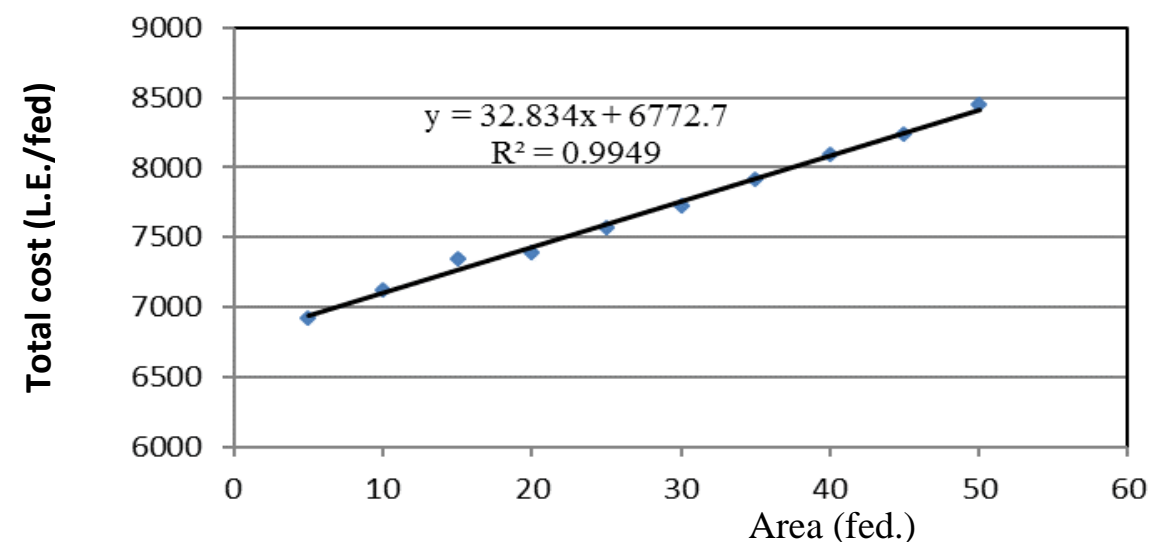

(A)

Effect of No. of shift on unit area cost

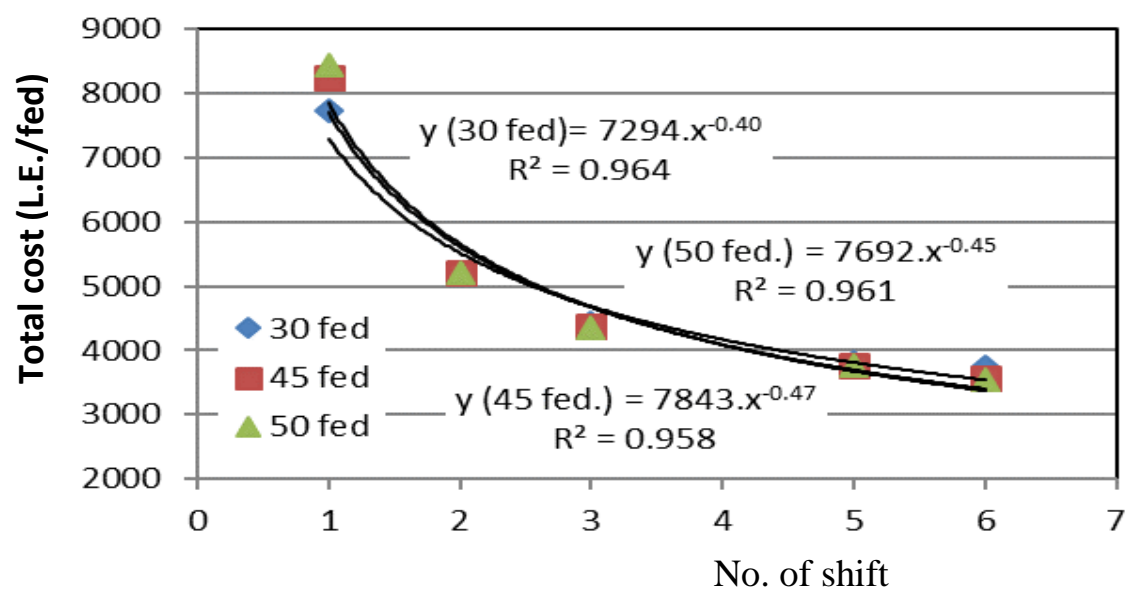

(B)

Fig. (2): Effect of system area and number of shifts on system total cost. 


\section{SUMMARY AND CONCLUSION}

Planning an irrigation network is to achieve suitable distribution of water and satisfy the hydraulics and economic rules. The objective of this research is to develop model to design, plane and manage an irrigation system subject to field geometry, soil, plant and irrigation system parameters. Planning or partitioning of the micro irrigation system was archived by solving equality subject to field area, dimensions, distance between lateral and emitters, constraints to limit lateral and manifold lengths and two other integer variables describes the arrangement of subunits around the main and submain lines. The Microsoft Excel Solver tool that applies the Generalized Reduced Gradient code was used to solve this part of the model. The model divides the field into subunits. The output variables are pipe lengths and diameters (lateral, riser, manifold, auxiliary, submain and main), the total number of subunits, number of sets (subunit parallel to the main line), and number of submain lines normal to the main line. Diameters of Lateral and manifold determined based on dividing $20 \%$ of the emitter nominal operating as allowable friction loss divided to $55 \%$ on lateral and $45 \%$ for manifold. Other network pipe diameters were designed based on water velocity limit to $1.5 \mathrm{~m} / \mathrm{sec}$. According to the soil and plant characteristics, the irrigation interval, duration and the possible number of shifts were determined. Based on the number of shifts the system was divided to number of subunits operate simultaneously. Base on the shift number the conveyance pipe diameters (main and submain), system water capacity, total dynamic head, pump power were re-estimated, therefore, the system total cost. The validity of the model was confirmed throughout two case studies. The first is to plan design and manage of $20 \mathrm{fed}$. $(300 \mathrm{~m}$ length and $280 \mathrm{~m}$ width) to irrigate trees $5 \mathrm{mx} 5 \mathrm{~m}$ spacing. The selection of the layout was among 5 patterns. Pattern No. E was the most economic option either in operating the system in one shift (the cost is 7343 LE.fed) or to reduce further cost to be 3861 L.E./fed.) in case of operate the system in four shifts. The other case study was to investigate the effect of system area (between 5 to 50 fed.) on system total cost. The results indicated that the cost increased linearly proportional to the increasing of the system area. The effect of number of shifts on total cost 
was also studied. Results showed that the relationship is power function where the total cost is inversely proportional to increasing the number of shifts.

\section{REFERENCES}

Abdel Wahed, M. H., 2002. Applying computer techniques for the determination of some crop water requirements and irrigation scheduling in designing drip irrigation system Unpublished Ph D Thesis. Faculty of Agric. El Fayoem, Cairo U.

El-Awady, M. N., and O. M. Ahmed, 1996. Planning trickle irrigation network. Exploration of modern technologies and computer in the field of agricultural engineering. Misr J of Ag. Eng. vol. 13 (4)

Goehring, L. D. (1976), Optimization of trickle irrigation system design unpublished. M.Sc. Thesis, Colorado State U., Fort Collins, Colo..

Hassanli , A. M., and Dandy, G. C. (1995). Least cost layout model for pressure irrigation system using genetic algorithms. Proc., Regional Conf. on water resource Management (WRM 95 ). Isfahan Uni. Iran.

Holzapfel, E. A., Marino, M. A., and Valenzuela, A. (1990). Drip irrigation nonlinear optimization model. J. irrig. and Drain. Eng. ASCE, 116(4), 479-496.

Ismail, S. M., E. R. El-Ashry , G. A. Sharaf and M, N. El- nesr. 2001. Computer aided design of trickle irrigation system. Misr $\mathrm{J}$ of Ag. Eng. vol. 18 (2)

Keller, J and D. Karmeli, 1975. Trickle irrigation design. Rain Bird Sprink. Co. Glendora, Cal. :133 P.

Keller, J. and R. D. Bliesner, 1990. Sprinkler and Trickle irrigation. An avi. Book, Champman \& Hall N.Y. 629 P.

Oron , G., and Karmeli, D. (1979). Procedure for the economical evaluation pf water networks parameters. Water Resource Bull., 15(4), 1050 -1059. 
Oron , G., and Walker, W. (1981). Optimal design and operation of permanent irrigation system Water Resource Res., 17(1), 11 -17.

Oron, G. (1982) Technical and economical consideration in the design of permanent conduit irrigation systems: A case study. Agric. Water management, 5(1), 15-27.

Soil conservation service (SCS), (1984). Trickle irrigation, US dept. of Agric. National Eng. Handbook. Ch.(15), Sec.(15).

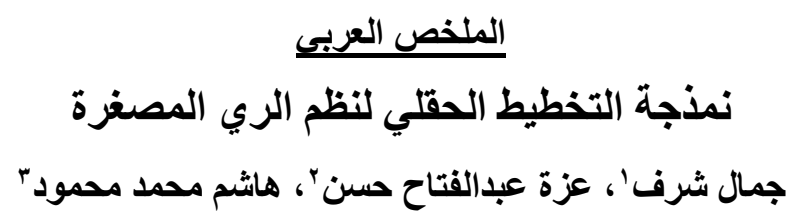

الهدف من هذا البحث هو إنشاء نموذج رياضي قادر على تخطيط وتصميم و إدارة نظم الري الري

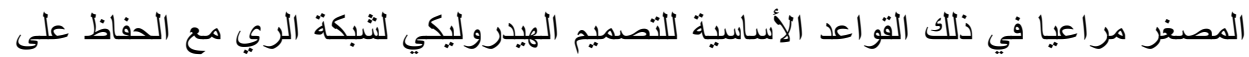

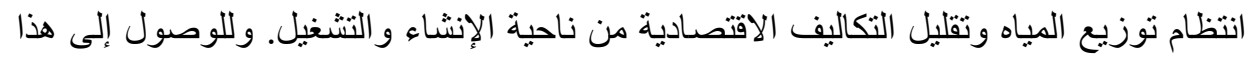
الهدف فقد تم تطوير نموذج قادر على حل خمسة نماذج للتخطيط (A, B, C, D, E)، ثلاثة النية

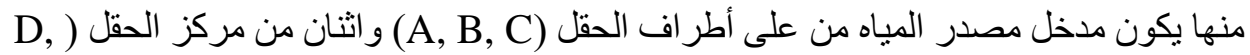

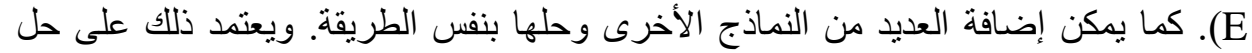
متساوية لبعض الثوابت و المتغيرات. و الثو ابت هي طول و وعرض الحقل الحقل و المسافة بين المنقطات

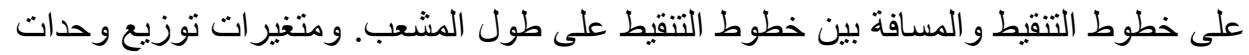

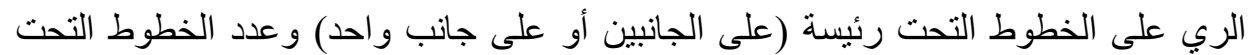

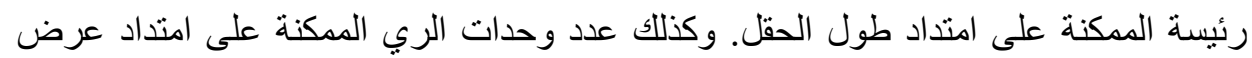

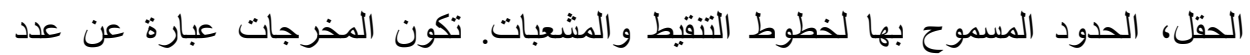

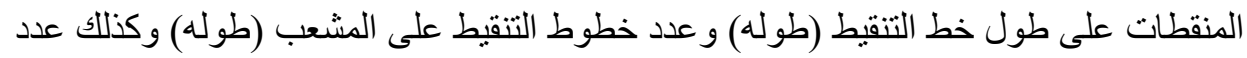

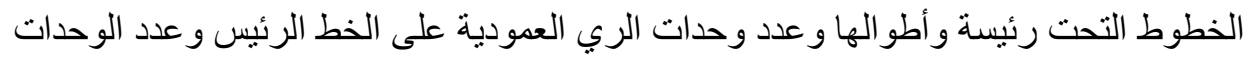

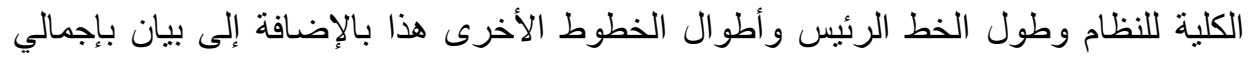

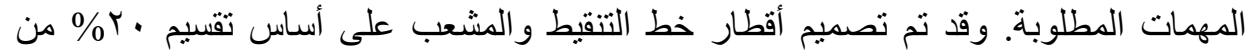

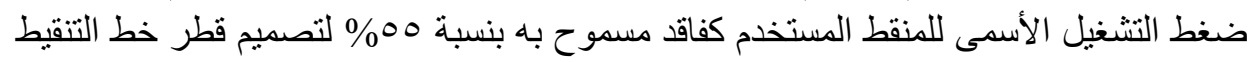

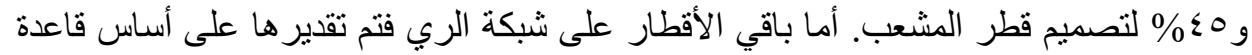

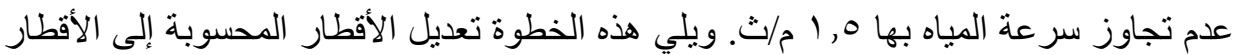

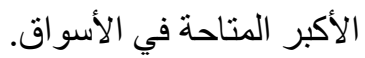

1 ـ أستاذ الهندسة الزراعية ـ قسم الأراضي ـ كلية زراعة سابا باشا - جامعة الإسكندرية

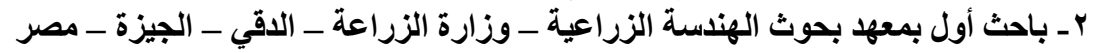

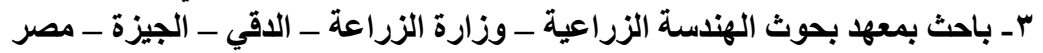


وبذلك يتم تقدير فو اقد الضغط الكلية داخل وحدة الري وبالتالي الاختلاف الفعلي في التصرف.

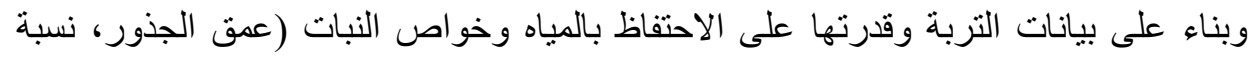

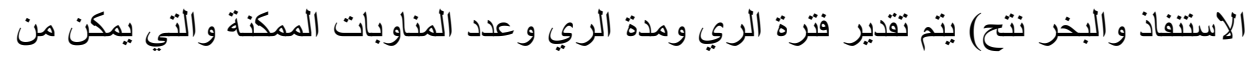
خلالها تقسيم الحقل إلى قطاعات تعمل بها عدد من حدات الري سويا.

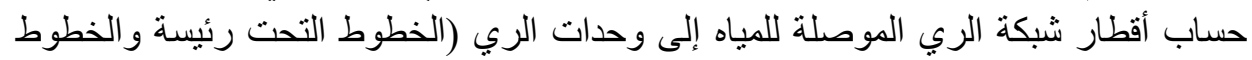
الرئيسة) حسب الوحدات العاملة معا وترتيبها وبالتالي ضاغط التشغيل الكلى وسعة الطلمبة الثبات

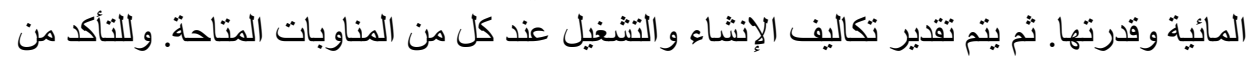
صلاحية هذا النموذج في تخطيط وتصميم وإدارة نظم الري المصغرة، فقد تم تقديم در اسة حالة

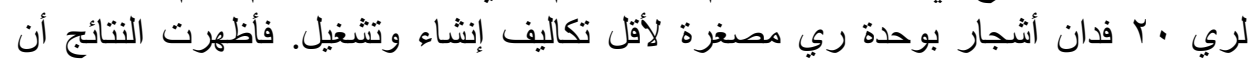

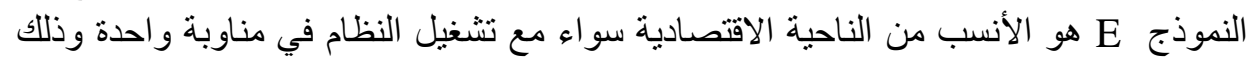

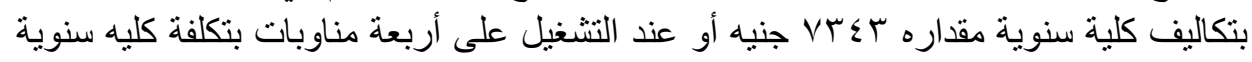

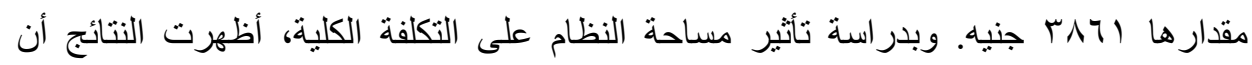
العلاقة خطية. ودراسة عدد المناوبات على التكلفة الكلية، أظهرت النتائج أن العلاقة عكسية التهاتية 